\title{
Schwannoma of the conus medullaris: a rare case
}

\author{
Suat Canbay ${ }^{1}$, Askin Esen Hasturk${ }^{1}$, Fatma Markoc ${ }^{2}$ and Sukru Caglar ${ }^{3}$
}

\begin{abstract}
Intradural schwannoma of the conus medullaris is a rare form of spinal neoplasm, which commonly occurs in the lumbar region. Conus medullaris level is unusual for schwannomas. A 49-year-old woman presented with chronic sciatica, mild bladder dysfunction, and paresthesia in the buttocks. Magnetic resonance imaging of the spine showed a mass lesion in the conus medullaris region with nerve compression. The tumor was completely resected and diagnosed histologically as schwannoma. The patient recovered after surgery. Clinical and radiologic features of this rare tumor are reviewed and are accompanied by literature findings.
\end{abstract}

Key words Schwannoma, conus medullaris, spine, surgery

Schwannoma is a benign, slow growing, encapsulated tumor arising from Schwann cells of the nerve sheath ${ }^{[1-3]}$. Although schwannomas account for $30 \%$ of all spinal neoplasms, the conus medullaris is an unusual location for these tumors ${ }^{[46]}$. We present a case of intradural schwannoma in the conus medullaris, which is very rare, and we reviewed the radiological and surgical features of this case in the context of the existing literature.

\section{Case Report}

A 49-year-old woman was admitted to our clinic with progressive lower back pain for 2 years. Her condition was treated as lumbar disc with radiculopathy. She described chronic sciatica, mild bladder dysfunction, and paresthesia in the buttocks. The symptoms had been gradually worsening in the last 2 months. Examination of the nervous system revealed paresthesia in the sacral dermatomes. No weakness or sensory loss in the lower extremities was recorded. No cutaneous stigmata of neurofibromatosis were seen. Magnetic resonance

Authors' Affiliations: 'Department of Neurosurgery, '2Department of Pathology, Oncology Training and Research Hospital, Demetevler, Ankara 06200, Turkey; ${ }^{3}$ Department of Neurosurgery, Ankara University Hospital, Talatpasa Bulvari, Altindag, Ankara 06230, Turkey.

Corresponding Author: Askin Esen Hasturk, Department of Neurosurgery, Oncology Training and Research Hospital, Vatan Caddesi, Demetevler, Ankara 06200, Turkey. Tel: +90-5337282904; Fax: +90-3123363439; Email: aehasturk@yahoo.com.

doi: $10.5732 /$ cjc. 011.10213 imaging (MRI) of the lumbar spine revealed a tumor in the conus medullaris region with nerve compression. The lesion located intradurally and was measured $4 \mathrm{~cm} \times$ $2.5 \mathrm{~cm} \times 2.5 \mathrm{~cm}$ (Figure 1). After T12-L1 laminectomy under microscopic visualization, a midline durotomy was performed and a well-defined, encapsulated, round lesion was found in the conus medullaris region (Figure 2). The tumor was completely resected. No neurologic complication was record. Postoperative MRI revealed no tumor (Figure 3).

Pathologic examination showed spindle-shaped cells with features of schwannoma in the lesion. Immunohistochemical staining was positive for S-100 protein (Figure 4). No evidence of nerve infiltration or mitoses was found.

\section{Discussion}

Schwannoma is a benign tumor of the peripheral nervous system that arises from Schwann cells and can occur in any body location where peripheral or cranial nerves are present ${ }^{[2-4]}$. Schwannomas account for approxima-tely $0.3 \%$ of primary intraspinal neoplasms. They tend to arise from the dorsal roots in the spinal region. The lumbar region is the most common location for spinal schwannomas ${ }^{[7-9]}$. Tumors arising in the cauda equina or around the conus medullaris can become larger than other spinal tumors because of the relative mobility of the roots and the wide diameter of the spinal canal. They may be well circumscribed, intradural or extradural, or combined intra-extradurally ${ }^{[10]}$. Schwannomas, together 

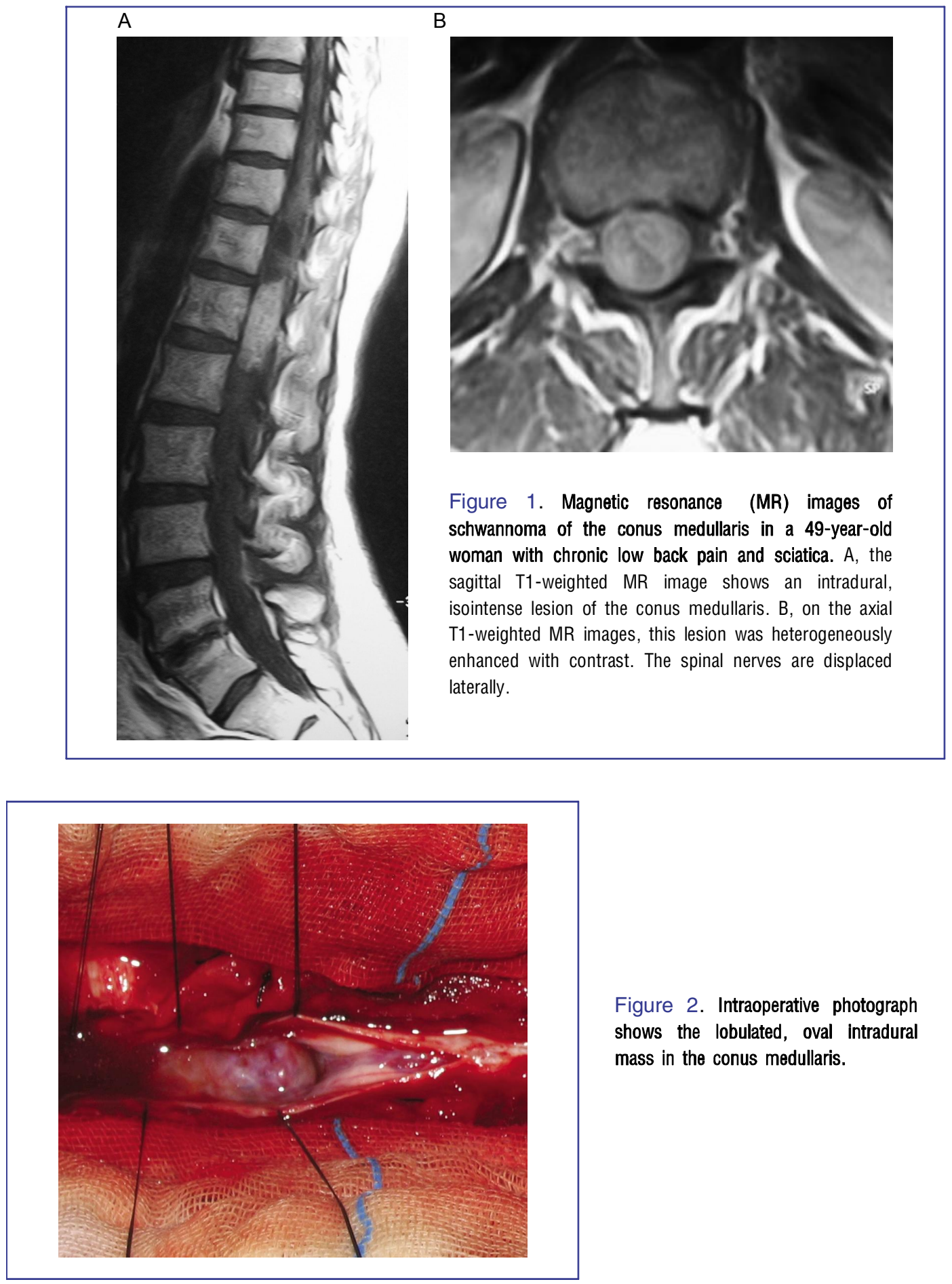

Figure 2. Intraoperative photograph shows the lobulated, oval Intradural mass in the conus medullaris. with meningiomas, are the most common intradural tumors. Generally, they occur between the fourth and sixth decades of life, and women and men are equally affected by this disease. Schwannoma can occasionally display degenerative changes like cyst formation, calcification, hemorrhage, and hyalinization.
The differential diagnoses of such a large cyst include a cystic schwannoma, cystic neurofibroma, ependymoma, epidermoid cyst, arachnoid cyst, cystic lymphangioma, cystic teratoma, and cystic meningioma ${ }^{[3,11,12]}$. Intraspinal schwannomas have no pathognomonic radiographic features. However, widening of the neural 

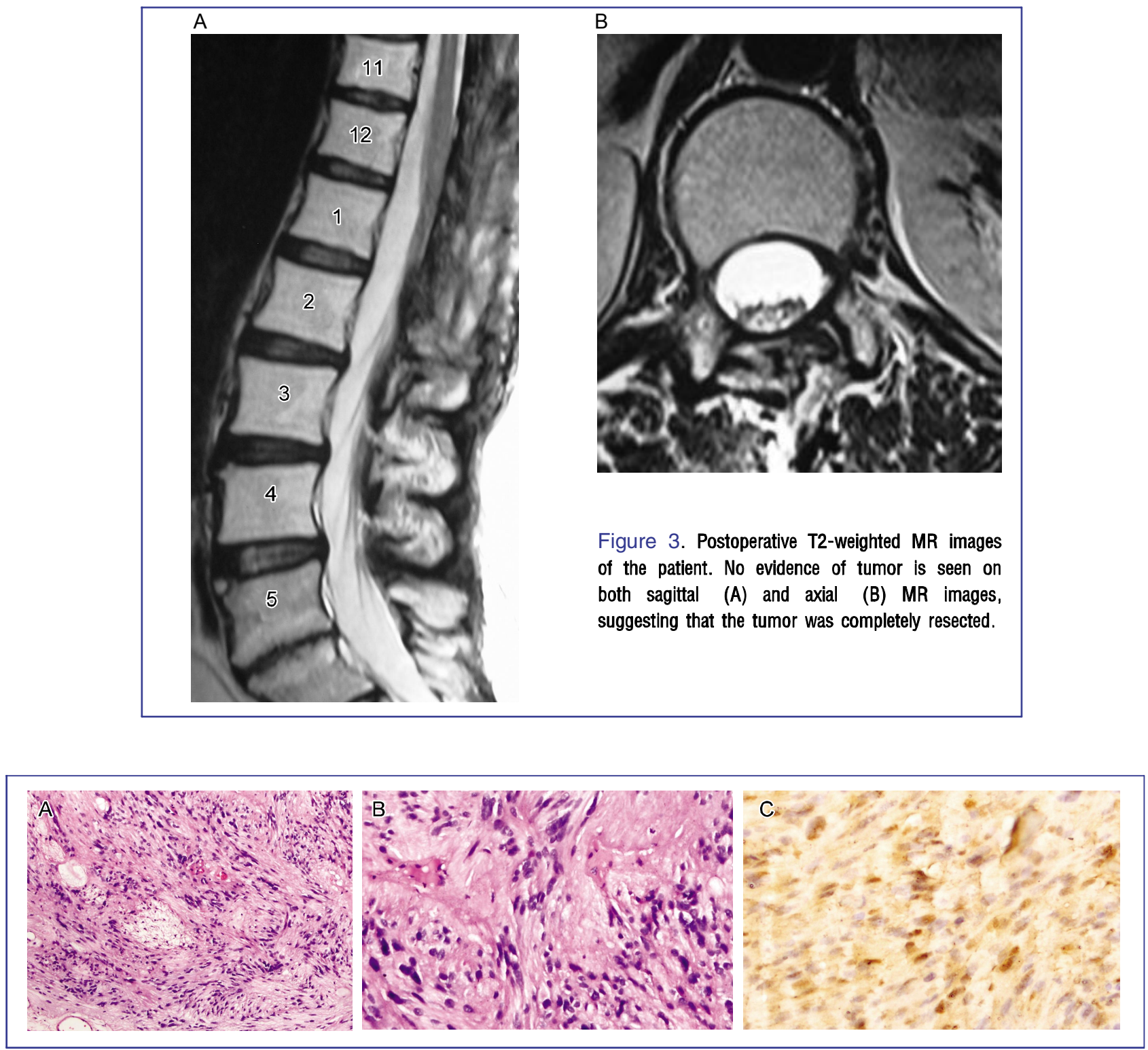

Figure 4. Morphology of the resected tumor. A, observing under a microscope, the tumor shows cellular and hipocellular areas (HE $\times 100)$. B, plumped spindle-shaped cells with palisading nuclei can be seen $(\mathrm{HE} \times 100)$. C, S-100 immunoreactivity is observed in tumor cells $(\mathrm{S}-100 \times 200)$.

foramen, erosion of the pedicle, increased interpedicular distance, and scalloping of the adjacent vertebral body may be seen by imaging examinations. MRI is the preferred imaging modality. Schwannomas generally have low-to-intermediate signal intensity on T1-weighted images. On T2-weighted images, they may be heterogeneous with focal areas of hyperintensity and hypointensity, corresponding to cyst formation, hemorrhage, dense cellularity, and collagen deposition ${ }^{[7,9,13]}$. Histological analysis is essential for definitive diagnosis. Schwannoma in its classic form consists of spindle-shaped cells with pale, eosinophilic cytoplasm arranged in two characteristic patterns: Antoni A (compact, hypercellular, well-organized spindle cells in a palisading pattern) and Antoni B (hypocellular, loose-textured pleomorphic cells with predominantly myxoid cytoplasm). In addition, schwannomas show diffuse immunoreactivity for $\mathrm{S}-100$ protein $^{[6-8,11]}$.

The treatment of schwannomas of the conus medullaris is similar to other spinal schwannomas and consists of radical surgical excision of the tumor and decompression of the spinal nerves ${ }^{[46,11]}$. Complete excision of tumor may prevent recurrence. Although schwannomas originate from nerve tissue, only $50 \%$ of 
cases have a direct connection with a nerve. Hence, complete excision without sacrificing nerve roots is feasible in most of the confined non-invasive cases. In our case, a laminectomy and total excision of the tumor were performed. Using the microscope with the aid of intraoperative monitoring (SSEP), we completely removed the tumor that was attached to the spinal nerves in the conus medullaris. The patient recorded no complication after surgery. Postoperatively, the sciatica was resolved and the patient was discharged in good health.

\section{References}

[1] Asahara $H$, Kawai $A$, Harada $Y$, et al. Spinal schwannomas: a review of 42 cases [J]. Acta Med Okayama, 1996,50(1):2528.

[2] Conti $P$, Pansini $G$, Mouchaty $H$, et al. Spinal neurinomas: retrospective analysis and long-term outcome of 179 consecutively operated cases and review of the literature [J]. Surg Neurol, 2004,61(1):34-43.

[3] Hasegawa M, Fujisawa $H$, Hayashi $Y$, et al. Surgical pathology of spinal schwannomas: a light and electron microscopic analysis of tumor capsules [J]. Neurosurgery, 2001,49 (6): $1388-1393$.

[4] Jinnai T, Koyama T. Clinical characteristics of spinal nerve sheath tumors: analysis of 149 cases [J]. Neurosurgery, 2005,56(3):510-515.

[5] Celli P. Treatment of relevant nerve roots involved in nerve sheath tumors: removal or preservation? [J]. Neurosurgery, 2002,51(3):684-692

[6] Celli P, Trillò G, Ferrante L. Spinal extradural schwannoma [J]. J Neurosurg Spine, 2005,2(4):447-456.

[7] Borges G, Bonilha L, Proa M Jr, et al. Imaging features and treatment of an intradural lumbar cystic schwannoma [J]. Arq Neuropsiquiatr, 2005,63(3A):681-684.

\section{Conclusions}

Intradural schwannoma of the conus medullaris region is a rare, benign and slow growing tumor. Generally, compression of nerve structures leads to clinical symptoms. Complete resection of schwannoma of the conus medullaris is advised to avoid recurrence if the tumor has no dense adhesion to neural tissue.

Received: 2011-05-23; revised: 2011-09-23; accepted: 2011-09-26.

[8] Colosimo C, Cerase A, Denaro L, et al. Magnetic resonance imaging of intramedullary spinal cord schwannomas. Report of two cases and review of the literature [J]. J Neurosurg, 2003,99(1):114-117.

[9] Hasegawa M, Fujisawa $H$, Hayashi $Y$, et al. Surgical pathology of spinal schwannoma: has the nerve of its origin been preserved or already degenerated during tumor growth? [J] Clin Neuropathol, 2005,24(1):19-25.

[10] McCormick PC, Post KD, Stein BM. Intradural extramedullary tumors in adults [J]. Neurosurg Clin N Am, 1990,1(3):591608.

[11] Kaneko $\mathrm{K}$, Kato $\mathrm{Y}$, Kojima $\mathrm{T}$, et al. Intraoperative electrophysiologic studies on the functions of nerve roots involved in cervical dumbbell-shaped schwannoma and their clinical utility [J]. J Spinal Disord Tech, 2006, 19(8):571-576.

[12] Kim P, Ebersold MJ, Onofrio BM, et al. Surgery of spinal nerve schwannoma. Risk of neurological deficit after resection of involved root [J]. J Neurosurg, 1989,71(6):810-814.

[13] Prevedello DM, Koerbel A, Tatsui CE, et al. Prognostic factors in the treatment of the intradural extramedullary tumors: a study of 44 cases [J]. Arq Neuropsiquiatr, 2003,61(2A):241-247. 